\title{
Cross-cultural priming and its effects on business ethical decision making
}

\section{John Tsalikis}

Ph.D., BMI Professor of Marketing, Department of Marketing, Florida International University, USA.

Stephanie M. Victoria

Honors College, Florida International University, USA.

(C) The Authors, 2017. This article is published with open access at ARMG Publishing.

\begin{abstract}
Priming is based on the notion that our emotions, actions, and perceptions, are strongly affected by unconscious environmental cues, as opposed to consciously processed stimuli. This research study adopts a priming approach to cross-cultural business ethics, and examines the effect of cultural priming on managerial ethical decision-making. Subjects were primed through exposure to a series of pictures depicting two cultures: either an American or an African culture. Using the scenario approach, subjects were asked to evaluate four short narratives describing an ethically questionable situation on an ethical scale. The four topics were: bribery, false advertising, pollution, and species extinction. The results show that groups which were primed with either culture found all the scenarios to be more unethical than those who were not primed at all. Significant differences between the two priming groups (African, American) were observed only for the species extinction scenario. More specifically, subjects that were primed with the African images viewed the extinction scenario as more unethical. Although cultural priming was not fully observed, both priming groups found all scenarios to be more unethical than the control group, meaning there was indeed a priming effect. These findings may lead to a better understanding of cultural differences and hopefully in diminished cultural misunderstanding and strife. It can also lead to better ethical decision-making by business people understanding the unconscious influences and biases they experience when dealing with different cultures and ethical dilemmas.
\end{abstract}

Keywords: Cross-cultural business ethics, priming, America, Africa, Corporate Social Responsibility

JEL Classification: M14.

\section{Introduction}

The study of ethics can be traced back as a branch of ancient Greek philosophy, and has been used for distinguishing social cohesion and morality. Philosophers like Plato and Socrates recognized the role of ethics in the manner we conduct basic human relationships: the way we perceive and behave towards others versus the manner we feel we should be treated. Ethical principles can derive from many sources within the individual's environment, and are a guide to moral behavior. Family customs, religion, schoolteachers, friends, neighborhoods, television, and the Internet are just some of the many sources that help develop moral behavior over time. Some cultures and groups can hold the same basic ethical principles, but apply them in completely different contexts. Ethical relativism is the view that ethical principles should be considered in the context of the individual's personal opinion, circumstances, cultural traditions, and era of history. Subsequently, the ethical implication and meaning assigned would depend on time, place, background, and parties involved (Lawrence and Weber, 2008).

The modern person is constantly barraged with thousands of environmental stimuli on a daily basis, most of which go unnoticed by the five senses. With the strong surge of digital media in recent decades, some experts even argue that we are exposed to more information in one day than our ancestors ever would encounter their entire lives (Hilbert, 2012). Though there has been an increase in accessible information. Our brains still do not have the capacity to store and access every piece of information we encounter. However, just because we are not consciously aware of the stimulus, does not mean it is not affecting us. This is the concept of priming: that easily accessible, unconscious environmental stimuli can still be processed and influence our moods, behaviors, thoughts, and opinions. 
The aim of this study is to determine whether priming of different types of cultural stimuli, specifically American and African, will influence people's perceptions of business ethical scenarios related to bribery, false advertising, pollution, and species extinction. Participants were primed by being shown pictures of African and American daily life, blending different dimensions of culture and other common symbolisms. They were then asked to take a brief ethics survey, rating the four scenarios on an ethical scale.

\section{Literature review}

\section{Principles of priming theory}

Priming finds its origins in a study conducted by Eagle, Wolitzky, and Klein (1966), who discovered that those primed with a picture of a tree trunk with a subliminal outline of a duck, included more duck-related content in the consequential task of drawing a nature scene. Those exposed to a plain tree trunk beforehand drew less ducks (See Figure 1). Even though the subjects did not consciously process the presence of the duck, the stimuli still influenced their psychological orientation and activated the idea of ducks without their consent. Since then, various studies have aimed to empirically demonstrate the effects of priming and provide proof of its existence utilizing different types of stimuli.

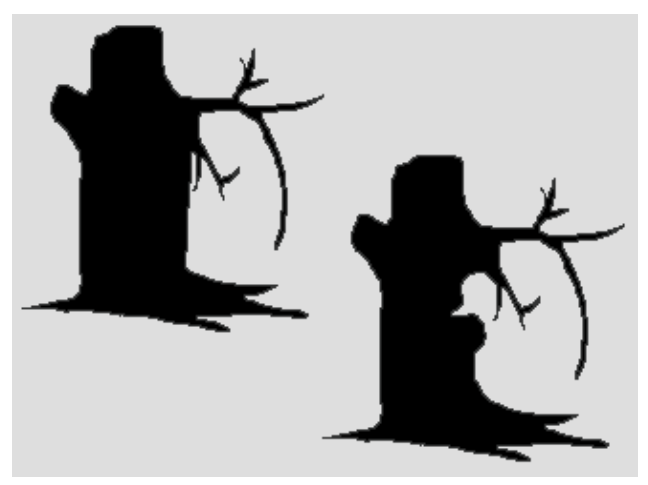

Figure 1. Plain tree trunks

Researchers have noted that priming effects are residual, and the effects are strengthened with increased knowledge accessibility and salience (emotional, motivational and cognitive significance) of the stimuli (Bargh, 1989; Higgins, 1996; Bargh and Chartrand, 2000). This means that priming effects can remain long after the stimuli are presented. Since our senses limit the amount of information processed at once, we tend to be unaware of the totality of stimuli that is influencing our perception in the moment (Dijksterhuis and Aarts, 2007). Such findings have certain insinuations about our understanding and the role of free will in decision-making, and that it may not influence our behavior as much as previously thought. These results have even graver indications about our cultural beliefs and stereotypes that constantly drive individual decisions: are these decisions truly informed, or are they merely founded on automatic associations and unconscious mimicry? Other studies have also found that social norms and stereotypes play a major role in subconscious knowledge accessibility: seeing a picture of a library urged individuals to speak more quietly; imagery of a briefcase and conference room encouraged some to behave more competitively (Aarts and Dijksterhuis, 2003). Even racist and hostile behavior has been proven to be a result of stereotype priming. Bargh et al. (1996) shows the influence of the African American stereotype prime. Subjects who were unconsciously primed with pictures of African American men and women reacted with hostility when they were told a computer had lost all their data, compared to subjects primed with Caucasian faces. Therefore, priming of African Americans in the media as aggressive and violent reinforces this priming effect and over time the stereotype is magnified and psychological accessibility and salience increases.

One study demonstrates how stereotypes and trait association affect our initial impressions of others through a mechanism known as "ideomotor action", or that imagining behavior increases the likelihood of actually doing it. Bargh et al. (1996) showed that subjects primed with words related to 'rudeness' were more quick to interrupt someone else's conversation afterwards compared to those primed with 'politeness,' who waited a significantly longer amount of time before interrupting a conversation. In the same study, subjects exposed to primes associated with "old age", were prompted to physically walk slower to their destination (Bargh et al., 1996).

Another priming experiment by Williams and Bargh (2008) revealed that even tactile priming of stimuli can illicit unconscious changes in perspective, or in this case, one's first impression of a stranger. Based on a prior asso- 
ciative theory of "warm-cold" as personality traits, the study had one group hold a hot cup of coffee during an elevator ride before a replicated 5-minute interaction with a stranger. After each interaction, the subjects were asked if they thought the person was capable, intelligent, skilled, etc. The subject who held iced coffee before meeting had more negative reactions toward the individual compared to the hot drink holders.

Researchers have also found that goals and motivations can be primed as well. Levesque and Pelletier (2003) note that those primed with "intrinsic motivation" words, such as "enjoying, delighted, challenging, mastering," relished the consequential experimental task of crossword puzzle solving much more than the group primed with "extrinsic motivation" words like "forced, expected, pressured, and controlled." Another experiment measured the effectiveness of subliminal goal-oriented priming by measuring the persuasiveness of a beverage ad on thirst. The subjects unconsciously primed with "thirst" drank more of an unfamiliar beverage, exhibiting the potential for priming to be utilized for helping orient a target population towards a desired outcome (Strahan et al., 2002). The same has been found in a study demonstrating the effects of emotional (affective) priming on motivation: "basic affective stimuli can sometimes act via unconscious processes to directly alter the target's incentive value." (Winkielman et al., 2005) It becomes clear that rationality is hardly the basis of a majority of our decisions and outward behaviors.

\section{Priming and decision making}

A major component of classical economics is rational choice theory. It assumes that individuals are selfinterested and always make logical and practical choices that give them the highest level of satisfaction or benefit (Sen, 1977). This belief is based on the premise that a majority of our actions, behaviors and decisions have their origins in the rational, conscious mind, and that humans exhibit more rationality than other species. The idea that humans are separate from animals through reason and language is a philosophical precedent set by René Descartes (1649, ed. 1993). He declared that mankind was superior to animals because animal behavior was considered mechanistic and automatic, while humans were allegedly more selfaware (or conscious). Our intelligence, intent, and ability to discern presumably coexist with the conscious component of the psyche. The truth is, humans are extremely biased and are subdued by environmental factors more than we care to admit (Zafirovski, 2003). Psychology has been exploring this question since Sigmund Freud's contention of the conscious and unconscious mind. His renowned iceberg comparison posits a different theory, in which he noted, "...the unconscious must be assumed to be the general basis of psychical life. The unconscious is the larger sphere, which includes within it the smaller sphere of the conscious...the unconscious is the true psychic reality..." (Freud, 1900, ed. 1931). Since then, psychologists have begun to justify Freud's claim: that subconscious automatic connections, associations, and stereotypes primarily drive our behaviors and decisions, rather than the conscious mind.

Bargh (1982), concludes: "processes and behaviors thought to be under our control and caused by intentional volition are actually the result of the constant and automatic interpretation of and reaction to stimuli in our environment." This automated mental process can often influence thoughts and behavior without the individual's knowledge. Bargh (1989) also explains how even simple autonomous behavior, such as deciding to drink juice instead of beer, is still influenced by unrecognized environmental cues in addition to the mental inputs which are not fully controllable.

Such skew of perception caused by unconscious environmental stimuli has great implications for fields such as: political psychology, philosophy, evolutionary biology, sociology, and business (Bargh, 2006).

\section{Priming applied to business}

Advances in priming research have caught the attention of many other fields such as business and marketing. For instance, Laran et al. (2011) demonstrates how different marketing tools, such as slogans and branding, have positive and negative priming effects. Consumers reacted more negatively towards slogans, causing them to act more fiscally conservative. Contrarily, brands had positive priming effects on consumption. The authors theorize that consumers unknowingly attribute human-like qualities to brands, making them more susceptible to persuasion. Slogans are perceived as more deceptive because consumers are aware of its blatant bias toward the product, which dwindles the influence of the prime.

Another study by Laran (2010) found that when it came to making choices for others, consumers made more indulgent choices, but when choosing for themselves, exhibited more self-control. The reason for this is because of differences in goal-pursuit. Consumers can understand their personal motivations and are capable 
of pursuing multiple goals when making one decision. On the other hand, when deciding for others, one does not consider that the other person would also want to achieve multiple goals and make conservative buying choices. Consumers assume others have simplified desires and goals. For example, when ordering food at a restaurant, the customer may desire to exhibit more self-control by perhaps ordering something healthier, or a smaller portion. If they are buying food for another person, they will be more inclined to purchase rich, tasty foods because they make inferences about that person's goals. This not only applies to buying behavior but can also help further our understanding of business and managerial decision-making, which is essentially making choices for other people.

Media and advertising are the primary drivers of culture and consumption decisions. These unintended priming effects may be of great concern, as many studies have found that media can have very negative, long-term priming consequences (Anderson and Bushman 2002). Harris et al. (2009) studied the impact of fast food advertising and its contribution to the nation-wide epidemic of childhood obesity. The authors stress the link between food cravings, exposure to media, and automatic eating behavior. Similar findings have been related to beliefs about alcohol consumption among children and adults (Roehrich and Goldman, 1995; Dunn and Yniguez, 1999). The same priming effect has also been observed for smoking ads (Pechman and Knight, 2002). These priming effects of advertising are ethically questionable and need to be reevaluated. The responsibility of influencing consumers in negative ways must fall on the private sector, which is producing these messages and advertising them for profit. One must also consider the extreme influence media can have on aggression and violent behavior (Anderson and Bushman, 2002), racial hostility (Bargh et al., 1996), self-image issues, social reality, and cultural beliefs (Wyer, 2008).

\section{Priming and cross-cultural business ethics}

Priming in ethics brings up many implications. If people can be so effortlessly swayed by unconscious factors, what does this mean for so-called "rational" decisions? Can the type of priming environment subliminally influence one's moral compass in the same way? Psychologists have often exposed the effects of priming on social norms, stereotypes, cultural ideologies, emotions, and goals (Bargh et al., 1996; Higgins, 1996; Bargh, 2006; Dijksterhuis and Aarts, 2007). The phenomenon of priming brings to question whether our moral worldview is subject to similar manipulations, more specifically when it comes to business ethics decisions. The cross-cultural approach to business ethics has been used frequently in recent years; however, the implicit role of priming in business ethics has yet to be explored in depth. In a heavily globalized economy, differences in culture produce differences in moral perceptions, which can end up affecting foreign business relationships. Vitell and Paollilo (2004) emphasize:

"....as businesses have expanded globally, the study of ethics has become increasingly important due to the various cultural/country environments in which global businesses operate on a daily basis issues such as intellectual property rights, insider trading and bribery are growing in importance due to the divergent views that different cultures might attach to these issues."

Cross-cultural business ethics studies aim to divert the study of business ethics from Western ideology to a deeper understanding of the moral systems that derive from the different conceptions of human nature (Hooker, 2007). Many researchers have conducted cross-cultural studies in relation to business ethics comparing various countries perceptions such as Russia, Slovenia, Turkey, the U.S. (Hisrich et al., 2003), and China, Korea, and Egypt (Ahmed et al., 2003). Maignan (2001) argues working towards high levels of corporate social responsibility will result in a competitive advantage because if the welfare and goodwill of consumers is actively supported, they will be willing to pay for more services. This is because the overall trust perceptions of consumers will be improved. The Ethics Resource Center (2005) also claims that business ethics pays off in the long run because increased personal wealth and wellbeing allows employees to work more efficiently and effectively.

In a cross-cultural comparison of Latin American ethics, Tsalikis (2014a), found significant differences in ethical behavior amongst Latin American countries albeit their common language and religious beliefs (Spanish and Catholicism, respectively). The author attributes these variances in morality to differences in historic and economic development, which is a combination of GDP, literacy, pollution, human rights perceptions, corruption, and other factors.

Tsalikis (2014b) attempted a cross-cultural priming approach to business ethics. Based on a similar priming technique found in Bargh et al., (1996), Tsalikis conducted an experiment comparing two cultures' (USA 
and Dominican Republic) business ethical decision-making by priming some groups with words pertaining to "politeness," while other groups were primed with "rudeness" in a sentence completion task. Subjects were then asked to evaluate ten ethical scenarios on an ethical scale. Tsalikis found that those primed with "politeness" viewed the ethical scenarios more negatively and sensitively than the group primed with "rudeness." He states:

"...The results imply that the knowledge of both ethical decision-making in business and our understanding of different cultures should improve. In a continuously globalizing society, it is our duty to familiarize and educate ourselves on the many cultural norms in order to unite and succeed in business. Social automaticity and priming occur most often in media and with the accessibility to Internet and, at any moment, cause a detrimental shift in perspective that could alter a proposition" (Tsalikis, 2014b).

A rooted socio-psychological understanding of ethics can help alleviate massive global problems caused by unethical business behavior such as social inequity, corruption, pollution, climate change, and human rights abuses. Unfortunately, there is still much to understand about the broad spectrum of ethics, which holds many different definitions and interpretations for each individual, subgroup, and culture. A priming approach to business ethics may unleash a deeper understanding of the subconscious, automatic behaviors, assumptions, ideals and values that affect our decision-making. It can also shed light on how to manipulate these unconscious external factors in order to foster a paradigm that promotes business ethical behavior, altruism and empathy, and ultimately, establish a stronger sense of social responsibility within the private sector. It would not be feasible to establish an international set of business ethics, but neither should these global and regional ethical dilemmas be ignored; instead, a cross-cultural understanding of each region with respect to its history and priming environment, would be more effective in navigating through an increasingly interconnected world.

\section{Hypotheses}

Based on previous research, the following hypotheses are proposed:

$>$ H1a: Respondents primed with the American culture will evaluate each of the 4 ethical scenarios as more unethical than respondents primed with the African stimuli.

$>$ H1b: Respondents primed with the American culture will evaluate each of the 4 ethical scenarios as more unethical than respondents not primed with any cultural stimuli.

$>$ H1c: Respondents primed with the African culture will evaluate each of the 4 ethical scenarios as less unethical than respondents not primed with any stimuli.

$>\mathrm{H} 2$ : Demographics will not be significant in influencing priming's effect on ethical attitudes.

\section{Methodology}

\section{Scenarios}

Most research in business ethics applies the scenario/vignette approach. This method portrays several short stories describing an ethically questionable issue and then prompts the respondent to evaluate the case on a numerical ethical scale. To determine the vignettes being used in the present study, a number of businessrelated scenarios were reviewed and pretested. For the sake of simplicity, and due to certain time restraints, only four scenarios were chosen. The four were selected based on their clarity to the participants. The ethical dilemmas addressed in the vignettes were bribery, false advertising, pollution, and species extinction (See Figure 2). The environmental business ethic was a new component being piloted in the study, as it has become a recent challenge, which calls for further investigation. Respondents were demographically distinguished according to their Gender, Place of Birth, and length of U.S. residency.

Please circle the level of ethicality for each scenario. Rate according to your opinion, there are no right or wrong answers. 
1. A businessman contacted a government official. The government official demanded the payment of a large sum of money for his "help" in obtaining a government contract. This is:
Unethical -
$-4 \quad-3$
$-2 \quad-1$
$\begin{array}{lll}0 & +1 & +2\end{array}$
$+3+4$
+5 Ethical

2. A company promised in its ads a "full money back guarantee". The company failed to keep this promise. This is:
Unethical -5
$-4 \quad-3$
$-2 \quad-1$
0
$+1$
$+2+3$
$+4+5$ Ethical

3. A company intentionally allowed a significant amount of toxic waste to spill into the local river.

This is:
Unethical -
$-4 \quad-3$
$-2 \quad-1$
$0+1$
$+2+3$
$+3+4 \quad+5$ Ethical

4. A timber company unintentionally contributed to the potential extinction of an endangered species of a flightless bird.

This is:
Unethical -5
$-4 \quad-3$
$-2 \quad-1$
$0+1 \quad+2$
$+3$
$+4 \quad+5$ Ethical

\section{Priming stimuli}

Figure 2. Ethics vignette questionnaire

For the present study, two allegedly dissimilar cultures were chosen: American and African. The United States is often portrayed in the American media as the wealthiest country, with strong legal accountability and enforcement systems, an established democratic political system, and is a world leader in diplomacy. However, African countries are described as having high rates of poverty, social unrest, vast political corruption, and weak governance. Both cultures have vastly different cultural and moral values. For this reason, U.S. culture acted as the "positive ethical prime," and African culture acted as the "negative ethical prime." It is important to note that cultures can only be labeled meaningfully in comparison with another, and that such allegations are not indicative of any absolute preconceptions (Hofstede, 2001).

The priming method chosen was through visual stimuli, a popular method seen in the priming field (Eagle et al., 1966; Bargh et al., 1996; Aarts and Dijksterhuis, 2003). Priming was achieved by showing the respondents a series of pictures depicting either African culture or American culture. The photos demonstrated daily life and symbolism in both cultures, including but not limited to: cuisine, weddings, religious worship, landmarks, fashion, art, music, political figures, workplaces, and holidays. Concerns regarding the bias of the photo selection based on the researchers' prior experiences and exposure to both cultures were taken into consideration. The pictures were reviewed in order to ensure no partiality was reflected in the photos. Any potential triggers of psychological harm towards the participants in the form of violent and offensive imagery were avoided. The goal was to create a realistic priming effect by showing participants pictures they might encounter if they were to simply Google search "African Culture" or "American Culture." Any perceived potential biases or stereotypes interpreted in the photos can only allow for a more realistic prime effect; especially since the subject population is in the United States. Findings in this regard can shed light on how certain cultures are portrayed in our environment and how these primes can impact our perception of others and automatic behavior towards them, as exhibited in Bargh et al. (1996).

\section{Procedure}

The data was gathered at a basic marketing class with mostly business students at a major southern university. The respondents were divided into three groups: two experimental and one control. One experimental group saw pictures of U.S. culture while the second experimental group viewed pictures from several African cultures. The control group was not primed with any pictures at all. The pictures were timed for 1.5 seconds one after the other, with a total of 36 American photos and 36 African pictures. A set of numbers labeled 1-3 were shuffled and disseminated to students while they waited outside the auditorium. Group 3 (control) was first called into the classroom and the questionnaires were distributed. This was to avoid incriminating discourse amongst the students that were waiting and curious about the procedure. It was imperative that they did not realize the correlation between the priming task and the ethics assessment. After the surveys were collected, the control subjects were asked to leave the room. Next, Group 1 (America) was asked to enter the room. Hence, if control subjects happened to recount the experience to other students, the new procedure would be unbeknownst to them. Group 1 was then primed with the corresponding photos, and the scenarios were issued without pretense to priming. The same steps were repeated for Group 2 (Africa). After each group completed the surveys, they were debriefed on the nature of the present study and were explained the principles of priming theory. 
Analysis

Using SPSS (Statistical Package for Social Sciences) the data was analyzed using a three way ANOVA (Analysis of Variance) comparing the average scores from the three experimental groups. A separate ANOVA was performed on each of the 4 scenarios. All responses were numerically coded and entered into SPSS. The independent variables were identified: gender, birthplace (inside or outside U.S.), culture of the prime, and number of years living in the U.S. Frequency tables for each scenario and all independent variables were generated for a better understanding of the sample population and overall results. Crosstabs were used to determine whether Gender, Place of Birth, Number of Years in the U.S. had an effect on ethical evaluations on each of the three groups.

\section{Results}

\section{Sample}

The sample came from a marketing class at a major university in South Florida. Among the 204 respondents, $60.8 \%$ were male, $69.6 \%$ consider themselves Hispanic, $60.3 \%$ were born in the US, and $59.8 \%$ lived all their life in the US. In the control group, there were 61 participants, 65 subjects in the Africa manipulation group, and 78 in the America manipulation group.

\section{Effects of priming}

As demonstrated in Table 1 below, the control group is significantly different from both manipulation groups for all four scenarios. The exposure to pictures resulted in respondents perceiving all 4 scenarios as more unethical. The control group perceived the bribery scenario and species extinction scenario as relatively neutral, or more morally acceptable, than the manipulation groups. Scenario 3 (pollution) was seen as the most unethical among all experimental groups.

Table 1. Comparison between the Control Group and the Two Manipulation Groups (Africa and U.S.)

\begin{tabular}{|c|c|c|c|c|c|}
\hline & Group & Mean & $T$-value & $d f$ & $p$-value \\
\hline Scenario 1 & Control & -.48 & & & \\
\hline \multirow[t]{2}{*}{ (Bribery) } & Africa & -3.31 & 6.30 & 124 & .00 \\
\hline & US & -3.77 & 9.86 & 137 & .00 \\
\hline Scenario 2 & Control & -2.92 & & & \\
\hline \multirow[t]{2}{*}{ (False Ad) } & Africa & -4.26 & 3.58 & 124 & .00 \\
\hline & US & -4.46 & 4.80 & 137 & .00 \\
\hline Scenario 3 & Control & -3.89 & & & \\
\hline \multirow[t]{2}{*}{ (Pollution) } & Africa & -4.91 & 3.46 & 124 & .00 \\
\hline & US & -4.95 & 3.97 & 137 & .00 \\
\hline Scenario 4 & Control & .11 & & & \\
\hline \multirow[t]{2}{*}{ (Extinction) } & Africa & -3.74 & 13.48 & 124 & .00 \\
\hline & US & -.51 & 2.69 & 137 & .00 \\
\hline
\end{tabular}

As seen in Table 2, for scenarios 1, 2 and 3, there are no significant differences between the ethical evaluations of the two manipulation groups (Africa and U.S.). However, for scenario 4, the respondents that were exposed to the African pictures perceived the act as more unethical than the group primed with American pictures, which believed the scenario was only slightly unethical. These findings ultimately reject hypotheses 1a-c for the first three scenarios, which stated that the American prime would have a more negative effect on business ethical perceptions than the African prime.

Table 2. Comparison between the Africa and US Exposure Groups

\begin{tabular}{|l|c|c|c|c|c|}
\hline & Group & Mean & $T$-value & $d f$ & $p$-value \\
\hline Scenario 1 & Africa & -3.31 & 1.31 & 141 & .19 \\
\hline & US & -3.77 & & & \\
\hline Scenario 2 & Africa & -4.26 & .98 & 141 & .32 \\
\hline & US & -4.46 & & & \\
\hline Scenario 3 & Africa & -4.91 & .74 & 141 & .45 \\
\hline
\end{tabular}




\begin{tabular}{|l|c|c|c|c|c|}
\hline & US & -4.95 & & & \\
\hline Scenario 4 & Africa & -3.74 & -17.38 & 141 & .00 \\
\hline & US & -.51 & & & \\
\hline
\end{tabular}

\section{Effects of demographic variables}

There was no significant difference in the way males and females evaluated all four scenarios. The genders had exactly the same reaction to all 4 scenarios as seen in Tables 1 and 2. Depending on the number of years living in the U.S., the results were also identical to Tables 1 and 2. Using the Place of Birth variable the results for the respondents born in the US were similar to Tables 1 and 2 above. The results for the respondents born outside the US are presented in Table 3 below. This and the Gender data prompt Hypothesis 2 to be accepted. However, respondents born outside the US who were exposed to the US pictures, perceived Scenario 1 as more unethical than the respondents that were exposed to the African pictures. Respondents born outside the US had a similar reaction to scenario 4 as observed before. Therefore, the Place of Birth variable did have a partial effect on business ethical perceptions.

Table 3. Effect on priming among people born outside the US

\begin{tabular}{|l|c|c|c|c|c|}
\hline & Group & Mean & $T$-value & $d f$ & $p$-value \\
\hline Scenario 1 & Africa & -2.81 & 2.27 & 56 & .02 \\
\hline & US & -4.13 & & & \\
\hline Scenario 2 & Africa & -4.33 & .42 & 56 & .67 \\
\hline & US & -4.45 & & & \\
\hline Scenario 3 & Africa & -4.81 & .99 & 56 & .32 \\
\hline & US & -4.94 & & & .00 \\
\hline Scenario 4 & Africa & -3.59 & -9.40 & 56 & \\
\hline
\end{tabular}

\section{Limitations}

Though popular, the vignette approach in business ethics exhibits certain drawbacks. For instance, participants can have a varying understanding of the types of consequences that apply to the scenario. Additionally, subjects may project imaginary details to the scenario in order to help them come to a conclusion (Hyman and Steiner, 1996). Finally, the subjects' past encounters with the different cultures being primed can also influence the outcome. This reiterates why the cross-cultural approach is crucial to understanding business ethics, because interpretation of morality differs based on personal experience and their respective automatic psychological connections.

\section{Discussion}

While the priming effect was significant for only one of the four scenarios, the significant difference between the control group (no priming) and both priming manipulations indicates that ethical perceptions were influenced when the negative consequences affect "real" human beings. I placed real in quotation marks because in the experiment respondents were shown only pictures of people. However, it is well established in neural psychology that the same neurons fire with either the word ROSE, the picture of a rose, or an actual rose (Rizzolatti and Craighero, 2004). Apparently, in this experiment, the presence of people, regardless of culture, made the respondents to perceive all of the four scenarios as more unethical. This can be attributed to the "empathy" phenomenon we feel the pain of another human being, rejoice in someone else's accomplishments, or scream with fear watching a demented killer chasing a group of teenagers in the typical horror movie. So, while "cultural" priming was not observed in the present study, "human" priming did certainly affect respondent ethical perceptions. It can also be attributed to the nature of the sample population: Millennials tend to be more tolerant of diversity (Gibson et al., 2009).

Some potential factors for the lack of "cultural" priming might be that while the pictures showed a clear difference between skin coloration, the situations depicted were quite similar; people shopping, playing sports, talking to friends, getting married etc. In a way the respondents ignored the peoples' skin and identified with the situation or what the people were doing. Future experiments should attempt to use biased cultural priming photos in order to explore the allegedly negative impact of prejudiced content on ethical behavior, perceptions, and decision-making. The neutrality of the photos made it harder for significant differ- 
ences in perceptions to be observed. While some similar influences were observed stemming from the demographic variable, the results were not consistent and the conclusions cannot be considered concrete because of the relatively small sample size. Another limitation of the study was that the age of the respondents did not have a broad range, with most of the respondents being in their low twenties. Future research should focus on a wider range of cultural and demographic respondent characteristics. Perhaps the outcome might have been manipulated had the subjects been baby boomers or older. Of interest is also the difference that intentions and the degree of negative consequences. Both of these variables were included in a limited range in this study. Further research should focus on a wider range of both of the aforementioned variables.

Firstly, the control groups reveal people's natural stance on these four ethical scenarios. In the college student's daily priming environment, one does not demonstrate a strong sense of moral discernment and judgment. We can see this in the lax responses to bribery and extinction, and the overall lower scores for all four scenarios. The intentional priming of people and culture was shown to have an impact on this. One possible explanation is simple: empathy and psychological mimicry. However, another explanation might be found in Laran's (2010) research, where it explores the idea of goal-pursuit for others. This experiment demonstrates how people make more indulgent and extreme decisions when they make a choice on behalf of other people, rather than for themselves. The effect of the "human" prime is seen in how when the subjects felt that their decisions impact actual human beings, their reactions tended to be more severe. This can shed light on how the message and imagery regarding humanity and unity can help lead to a stronger demand for justice and moral reconciliation. By promoting cultural understanding, empathy, and benevolence, there is hope in seeking to achieve moral integrity. A "human priming" approach might be beneficial way to tackle these ethical issues by encouraging a sense of personal responsibility for another's wellbeing.

Secondly, the results also show that Scenarios 2 and 3 (false advertising and pollution) are more widely accepted as more unethical than Scenarios 1 and 4 (bribery and extinction). Even though bribery is technically illegal, this might reveal that people are still inclined to allow it to continue. The same concept applies to species extinction. They might be aware it is happening, but the respondents do not see how it has an impact on their personal lives or their loved ones, and therefore, are more lenient of its incidence. The parties afflicted in Scenarios 1 and 4 are seemingly more distant (or non-human), and respondents could not personally empathize with those vignettes. However, Scenarios 2 and 3 are seen to impact a larger human population of innocent bystanders, and therefore exhibited more adverse reactions than the other two scenarios. Another factor can be the feasibility of addressing the ethical dilemma itself. Political corruption and species extinction specifically are more complex, systematic issues. The obstacles for overcoming those two appear more overwhelming in the respondents' minds. That being said, the weaker responses to Scenarios 1 and 4 indicate that people generally do not feel empowered to tackle these issues to demand justice, but might actually feel helpless about it and be disinclined to empathize.

In regards to the variable results for Scenario 1 (bribery), those born outside the U.S. might have memories or negative reinforcement of corrupt political climates. The sample also consisted of $60 \%$ first, second, or third-generation Hispanic students, so a majority of the respondents do not strictly engage only in American culture. Therefore, when primed with U.S. culture - which is often associated with "justice, opportunity, and abundance" compared to their country of origin-subjects then judged the situation more harshly.

Additionally, it was noteworthy how participants reacted the species extinction vignette (Scenario 4). It appears the pictures in the African prime incited more environmental concern than those primed with the U.S., even though it was the only ethical scenario where the consequences did not directly impact humans. This might be due to the presence of more pristine natural landscapes in the African prime, but respondents did not seem to feel the same way about pollution. However, according to Hofstede's $(2001 ; 2010)$ cultural dimensions, African culture is more feminine and collectivist than American culture. Perhaps the priming of dominant and aggressive behavior in American culture causes an indifferent or positive reaction towards species extinction. Dominance can be translated into dominance over humans as well as other non-human species (anthropocentrism). The collectivist dimension is a key component in attaining a mature environmental ethic for properly executing impactful CSR initiatives, and for promoting generally positive company culture (Wang and Young, 2014).

Moral cohesion on a global scale may seem far-fetched, but it is attainable. With ongoing globalization, the idea of culture itself is changing. The walls of cultural differences may no longer strictly divide ethical perceptions, as worldviews continue to evolve and mesh together. Priming exerts a real influence in our uncon- 
scious decision-making and its effects on ethical judgments and ethical decision-making should be studied. Ultimate ethical decision-making might not reside in our logical cerebral cortex but in our animalistic limbic and reptilian brains. The control that humans have over the latter two sections of the human brain is questionable, but advances in brain manipulation might lead to more ethical business decision making, paving the path toward deeper understanding of promoting ethical sustainable behaviors among all stakeholders.

Finally, it is important to note that priming on its own cannot change behaviors and actions, but only when combined with the individual's motivational state and eliciting a desire to pursue a change in mood. Priming research has often been criticized for focusing too much on a single prime, and not being studied within a relevant context (McNerney, 2011). This means that priming does not occur in isolated incidents but happens in real-time, mixed with several thousand other stimuli in our day-to-day lives. There is a need for priming research to now answer these types of questions. Bargh (2006) confronts this issue and offers criticisms to his own peers and the socio-psychology community as a whole: "By constraining and informing our models of nonconscious processes in social psychology with theoretical and empirical developments in these related fields of inquiry, we can help assure that research in our own little neck of woods will continue to matter in the long run, and to the larger picture". Our understanding of priming theory is still relatively limited, but developments in the field reveal its potential in helping understand decision-making on a deeper level.

\section{Compliance with ethical standards}

This study did not receive any special funding. The author declares that he has no conflict of interest. Ethical Approval: Humans subjects were involved in this study. All procedures performed in this study involving human participants were in accordance with the ethical standards of the institutional and national research committee and with the 1964 Helsinki declaration and its late amendments. Informed consent was obtained from all individual participants included in the study.

\section{References}

1. Aarts, H., and A. Dijksterhuis (2003). The Silence of the Library; Environmental, Situational Norm, and Social Behavior. Journal of Personality and Social Psychology, 84(1), 18-28.

2. Ahmed, M.M., K.Y. Chung, and J.W. Eichenseher: 2003, 'Business Students' Perception of Ethics and Moral Judgment: A Cross-Cultural Study', Journal of Business Ethics 43(1/2), 89-102.

3. Anderson, C. A., and B. J. Bushman (2002). The Effects of Media Violence on Society. Science, 295, 2377-2379.

4. Bargh, John A. (1982). Attention and Automaticity in the Processing of Self-relevant Information. Journal of Personality and Psychology, 43, 425-436.

5. Bargh, John A. (1989). Conditional Automaticity: Varieties of automatic influence in social perception and cognition. Guilford Press, 3-51.

6. Bargh, John A., Mark Chen and Lara Burrows. (1996). Automaticity of Social Behavior: Direct Effects of Trait Construct and Stereotype Activation on Action. Journal of Personality and Social Psychology, 71, 230-244.

7. Bargh. John A. and T.L. Chartrand. (2000). The Mind in the Middle: A Practical Guide to Priming and Automaticity Research, in H. T. Reis and C. M. Judd (Eds.) Handbook of Research Methods in Social and Personality Psychology, NY: Cambridge University Press, 253-285.

8. Bargh, John A. (2006). What have we been Priming All these Years? On the Development, Mechanisms, and Ecology of Nonconscious Social Behavior. European Journal of Social Psychology, 36, 147-168.

9. Dijksterhuis, A., T. L. Chartrand, and H. Aarts. (2007). Automatic Behavior, in J. A. Bargh (Eds.), Social Psychology and the Unconscious: The Automaticity of Higher Mental Processes, Philadelphia: Psychology Press, 51-131.

10. Descartes, René (1649, ed. 1993). Animals are Machines, in Environmental Ethics: Divergence and Convergence, eds. S. J. Armstrong and R. G. Botzler (New York: McGraw-Hill), 281- 285.

11. Dunn, M.E. and R.M. Yniguez (1999). Experimental Demonstration of the Influence of Alcohol Advertising on the Activation of Alcohol Expectancies in Memory Among Fourth and Fifth-grade Children. Experimental and Clinical Psychopharmacology, 7, 473-483.

12. Ethics Resource Center. (2005). National Business Ethics Survey. Washington, D.C: Ethics Resource Center.

13. Eagle, M., D.L. Wolitzky, and G.S. Klein. (1966). Imagery: Effects of a Concealed Figure in a Stimulus. Science, 151 (Feb 18), 837-839. 
14. Gibson, Jane Whitney; Greenwood, Regina A; Murphy, Edward F, Jr. (2009). Generational Differences In The Workplace: Personal Values, Behaviors, And Popular Beliefs. Journal of Diversity Management; Third Quarter. 4(3).

15. Harris, Jennifer L., John A. Bargh and Kelly D. Brownell. (2009). Priming Effect of Television Food Advertising on Eating Behavior. Health Psychology, 28: 404-413.

16. Higgins, E.T. (1996). Knowledge Activation: Accessibility, Applicability, and Salience, in E.T. Higgins, and A.W. Kruglanski (Eds.), Social Psychology: Handbook of Basic Principles, NY: The Guilford Press, 133-168.

17. Hilbert, M. (2012). How much information is there in the "information society"? Significance, 9(4), 8-12.

18. Hisrich, R.D., B. Bucar, and S. Oztark. (2003). A Cross-Cultural Comparison of Business Ethics: Cases of Russia, Slovenia, Turkey, and United States, Cross Cultural Management 10(1), 3-28.

19. Hofstede, Geert. (2001). Culture's Consequences: Comparing Values, Behaviors, Institutions, and Organizations Across Nations. Second Edition, Thousand Oaks CA: Sage Publications.

20. Hooker, J. (2007). Cross-Cultural Issues In Business Ethics. Carnegie Mellon University. Retrieved from: http://web.tepper.cmu.edu/jnh/aib.pdf

21. Hyman, M.R., \& Steiner, S.D. (1996). The Vignette Method in Business Ethics Research: Current Uses, Limitations, and Recommendations. Studies, 20(100.0), 74-100.

22. Laran, J. (2010). Goal Management in Sequential Choices: Consumer Choices for Others are More Indulgent than Personal Choices. Journal of Consumer Research, 37(August), 304-314.

23. Laran, Juliano, Amy Dalton and Eduardo Andrade. (2011). The Curious Case of Behavioral Backlash: Why Brands Produce Priming Effects and Slogans Produce Reverse Priming Effects. Journal of Consumer Research, 37, 99-1014.

24. Lawrence, A., \&; Weber, J. (2008). Business and Society: stakeholders, ethics, public policy. New York, NY: McGraw-Hill Irwin.

25. Levesque, C., and L.G. Pelletier. (2003). On the Investigation of Primed and Chronic Autonomous and Heteronomous Motivational Orientations. Personality and Social Psychology Bulletin, 29(12), 1570-1584.

26. Maignan, I.: 2001, "Consumers" Perceptions of Corporate Social Responsibilities: A Cross Cultural Comparison', Journal of Business Ethics 30(1), 57-72.

27. McNerney, Sam. (2011). Priming Revisited. Retrieved from. http://whywereason.com/ 2011/07/11/priming-revisited/

28. Pechman, C., and S. J. Knight. (2002). An Experimental Investigation of the Joint Effects of Advertising and Peers on Adolescents' Beliefs and Intentions about Cigarette Consumption. Journal of Consumer Research, 29, 5-19.

29. Rizzolatti, G., \& Craighero, L. (2004). The mirror-neuron system. Annu. Rev. Neurosci., 27, 169-192.

30. Roehrich, L., and M. S. Goldman. (1995). Implicit Priming of Alcohol Expectancy Memory Processes and Subsequent Drinking Behavior. Experimental and Clinical Psychopharmacology, 3, 402-410.

31. Sen, A.K. (1977). Rational Fools: A Critique of the Behavioral Foundations of Economic Theory. Philosophy \& Public Affairs, 6(4), 317-344.

32. Strahan, E.J., Spencer, S.J., and Zanna, M.P. (2002). Subliminal Priming and Persuasion: Striking while the Iron is Hot. Journal of Experimental Social Psychology, 38, 556-568.

33. Tsalikis, J. and B. Seaton. (2006). Business Ethics Index: Measuring Consumer Sentiments toward Business Ethical Practices, Journal of Business Ethics 64(4), 317-326.

34. Tsalikis, John. (2014a). Business Ethics Index: Latin America. Journal of Business Ethics, 119(2), 209-218.

35. Tsalikis, John. (2014b). The Effects of Priming on Business Ethical Perceptions: A Comparison Between Two Cultures. Journal of Business Ethics, 1-9.

36. Vitell, S.J. and J.G.P. Paolillo: 2004, A Cross-Cultural Study of the Antecedents of the Perceived Role of Ethics and Social Responsibility, Business Ethics 13(2-3), 185+.

37. Wang, X., \& Young, M.N. (2014). Does collectivism affect environmental ethics? A multi-level study of top management teams from chemical firms in China. Journal of Business Ethics, 122(3), 387-394.

38. Williams, L.E., and J.A. Bargh. (2008). Experiencing Physical Warmth Promotes Interpersonal Warmth, Science, 322, 606-607.

39. Winkielman, P., K.C. Berridge, and J.L. Wilberger. (2005). Unconscious Affective Reactions to Masked Happy Versus Angry Faces Influence Consumption Behavior and Judgments of Value. Personality and Social Psychology Bulletin, 31, 121-235. 
40. Wyer, R.S. (2008). The Role of Knowledge Accessibility in Cognition and Behavior: Implications for Consumer Information Processing in Handbook for Consumer Psychology, (Eds.) C.P. Haugtvedt, P. Herr, and F.R. Kardes, NJ: Erlbaum, 31-76.

41. Zafirovski, M. (2003). Human rational behavior and economic rationality. Electronic Journal of Sociology, 7(2), 1-34. 